Vol. 7(8), pp. 183-188, August 2015

DOI: $10.5897 / J P P 2015.0353$

Article Number: 7E43C2654313

ISSN 2141-2502

Copyright (c) 2015

Journal of Pharmacognosy and Phytotherapy

Author(s) retain the copyright of this article

http://www.academicjournals.org/JPP

\title{
Preliminary screening of anti-inflammatory effect of phytochemicals on chemotaxis of human neutrophils
}

\author{
Uthayashanker R. Ezekiel` and Rita M. Heuertz \\ Department of Biomedical Laboratory Science,Doisy College of Health Sciences,Saint Louis University, \\ 3437 Caroline Street,Saint Louis, USA.
}

Received 24 May, 2015; Accepted 23 July, 2015

\begin{abstract}
Neutrophils are leukocytes that are actively recruited to sites of tissue infection and/or injury by directed movement (chemotaxis). In vitro assessment of inhibition of neutrophil chemotaxis is a physiologic indicator of anti-inflammatory potential. To identify nontoxic, anti-inflammatory agents, plant-derived compounds (curcumin, resveratrol, rosmarinic acid and piperine) were assessed for effects on in vitro neutrophil movement. Effects were determined on directed migration (chemotaxis) towards the potent chemoattractant of bacterial cell wall origin, f-met-leu-phe (fMLP). Curcumin significantly inhibited neutrophil chemotaxis in a concentration-dependent manner with statistically significant inhibition at 50 and $100 \mu \mathrm{M}$. Similarly, resveratrol $(25,50,100 \mu \mathrm{M})$ and rosmarinic acid $(100$ $\mu \mathrm{M})$ significantly inhibited fMLP-induced chemotaxis in concentration-dependent manners. Piperine had no effect on neutrophil chemotaxis. These results indicate that curcumin, resveratrol and rosmarinic acid have the potential to elicit anti-inflammatory effects.
\end{abstract}

Key words: Neutrophils, phytochemicals, chemotaxis, inflammation.

\section{INTRODUCTION}

An important in vivo biological event is chemotaxis, which is directed cell movement towards a chemical or biological agent. Chemotaxis occurs in many cell types with examples being leukocyte influx into an inflammatory nidus, migration of endothelial cells for blood vessel formation during angiogenesis, development of an embryo and cancer cell metastasis. Chemotaxis is regularly assessed in immune cells where their mobilization and deployment to sites of inflammation are integral parts of the immune response (Kruger et al., 2015).
One immune cell type, the polymorphonuclear neutrophil (PMN), has been well studied for its chemotactic behavior relevant to its important role in innate immunity and inflammation (Headland and Norling, 2015). Recruitment of neutrophils to sites of inflammation or injury involves the following commonly recognized steps: tethering, rolling, adhesion, crawling and endothelial transmigration (Kolaczkowska and Kubes, 2013). Neutrophil chemotaxis is induced by chemoattractants such as chemokines (interleukin-8: IL8), bacteria-derived agents (f-met-leu-phe: fMLP) and

*Corresponding author. E-mail: vezekiel@slu.edu.

Author(s) agree that this article remain permanently open access under the terms of the Creative Commons Attribution License 4.0 International License 
vasculature-derived components (complement proteins such as C5a) (McNeely et al., 1993). Regardless of the cue, neutrophils in circulation first recognize chemotactic signals in the endothelium close to an inflammatory site, roll along the endothelium and extravasate into the tissue where they fight infections and interact with other cells of the immune system. Neutrophils are the first cells to arrive at an inflammatory site and they do that in massive numbers (Bardoel et al., 2014).

Therefore, assessment of neutrophil chemotaxis is an important early function in acute inflammation. Noteworthy is the fact that impaired recruitment or inappropriate or excessive activation of neutrophils can lead to disease states such as rheumatoid arthritis, inflammatory bowel disease and chronic obstructive pulmonary disease (den Broeder et al., 2003; Kaur and Singh, 2013; Larmonier et al., 2011). It is for this reason that neutrophils have become targets for pharmaceutical approaches to functional regulation. Constant concerns about an ever-expanding population of patients with inflammation-mediated diseases coupled with lack of nontoxic yet efficacious anti-inflammatory agents are sufficient reasons to continue the search for other therapeutic options and strategies. One alternative strategy is the use of plant compounds that have antiinflammatory properties.

Reports indicate anti-inflammatory properties of rosmarinic acid (derived from rosemary), resveratrol (from skins of red grapes), curcumin (derived from turmeric) and piperine (derived from black pepper). Rosmarinic acid caused susbstantial reduction in inflammation in three different rat models of inflammation, local (carrageenin-induced paw edema) and systemic (liver ischemia/reperfusion injury, thermal injury) (Rocha et al., 2015). Additionally, it reduced inflammation (example, neutrophil infiltration) in LPS-challenged horses (Pearson et al., 2012) and reduced number of inflammatory cells in the airways of an experimental model of respiratory allergy (Costa et al., 2012). Resveratrol inhibited inflammation, with reduced neutrophil infiltration as a marker, in a rat cerebral ischemia/reperfusion model of stroke (Fang et al., 2015) and inhibited airway inflammation and hyperreactivity in mice (Zang et al., 2015). Curcumin, administered as oral doses, inhibited neutrophil infiltration into lavage fluid in mouse models of extrinsic (Hemophilus influenzainduced) and intrinsic (tumor-induced) airway inflammation (Moghaddam et al., 2009), and significantly inhibited neutrophil infiltration and inflammatory cytokine production in a murine model of asthma (Narumoto et al., 2012). Piperine inhibited inflammation in a rat periodontitis model (Dong et al., 2015) and reduced proinflammatory cytokine levels, infarct volume and neuronal loss in a rat model of stroke (Vaibhav et al., 2012).

Given the cited reports, plant-derived compounds with anti-inflammatory potential, specifically curcumin, resveratrol, rosmarinic acid and piperine, were selected for assessment of effects on chemotaxis of human neutrophil. These compounds were assessed by the leading front method of chemotaxis to determine their effects on fMLP-induced chemotaxis of human neutrophils (Kinane et al., 1989). Other reports document anti-inflammatory potential of each one of these plant compounds (Budhiraja and Dhingra, 2014; HassanKhabbar et al., 2010; Nonose et al., 2014; Sabina et al., 2011) as well as nontoxic host effects (Wang et al., 2015; McCrea et al., 2015).

\section{MATERIALS AND METHODS}

\section{Isolation of human neutrophils}

Heparinized venous blood was obtained from normal healthy, medication-free human donors after receiving informed consent following a protocol approved by the Saint Louis University Institutional Review Board. Neutrophils were isolated by dextran sedimentation and Ficoll-Hypaque density gradient centrifugation (Boyum, 1968). Contaminating erythrocytes were removed by hypotonic lysis. Cell purity was determined by differential counts of Wright-Giemsa stain (Sigma-Aldrich, St. Louis, MO) of cytospin preparations (routinely $>95 \%$ ) and neutrophil viability was determined by trypan blue (Sigma-Aldrich) exclusion (routinely $>98 \%$ ).

\section{Phytochemical compounds}

The phytochemicals, curcumin, resveratrol, rosmarinic acid and piperine were obtained commercially (Sigma-Aldrich). The compounds were solubilized in dimethylsulfoxide (DMSO: SigmaAldrich) at $100 \mathrm{mM}$ stock concentrations and stored at $-80^{\circ} \mathrm{C}$. Phytochemicals used for chemotaxis were assessed at several concentrations $(0.01,0.1,1,10,100 \mu \mathrm{M}$ : concentrations were generated by diluting stock solutions in chemotaxis buffer (formulation described below)). The highest concentration $(0.1 \%)$ of DMSO used for solubilization of plant-derived compounds was assessed in the assay as the vehicle control.

\section{Leading front method of neutrophil chemotaxis}

Appropriate concentrations of the bacteria-derived chemoattractant, f-met-leu-phe (fMLP: Sigma-Aldrich), was determined empirically by ascertaining concentration response curves of $\mathrm{fMLP}$. Chemotaxis was measured using the leading front method of Zigmond and Hirsch (1973) as modified by Heuertz et al. (1999). Briefly, neutrophils were pretreated $\left(10 \mathrm{~min}, 37^{\circ} \mathrm{C}\right)$ with plant-derived compounds in chemotaxis buffer consisting of Hanks' balanced salt solution (Sigma-Aldrich) containing N-2-hydroxyl-ethyl-piperazineN'-2-ethanesulfonic acid (Hepes, $10 \mathrm{mM}, \mathrm{pH}$ 7.4: Sigma-Aldrich) and bovine serum albumin (1\%: Sigma-Aldrich). Chemoattractant (fMLP) or buffer control (random neutrophil movement) was added to wells of the lower chamber in the chemotaxis assembly. A cellulose-nitrate filter $(3 \mu \mathrm{m}$ pore size: Sartorius Filters, Inc., Hayward, CA) was positioned on top of the lower chamber.

The 48-well chemotaxis apparatus (Neuroprobe, Cabin John, MD) was assembled and neutrophils $(200,000$ in $50 \mu \mathrm{l} /$ well) were added to wells of the upper chamber. After set-up, the chemotaxis apparatus was incubated $\left(35 \mathrm{~min}, 37^{\circ} \mathrm{C}\right)$ to allow time for the neutrophils to detect and react to the fMLP. After incubation, filters were removed from the chemotaxis assembly, fixed in isopropanol and stained with Harris acid hematoxylin (Sigma- 


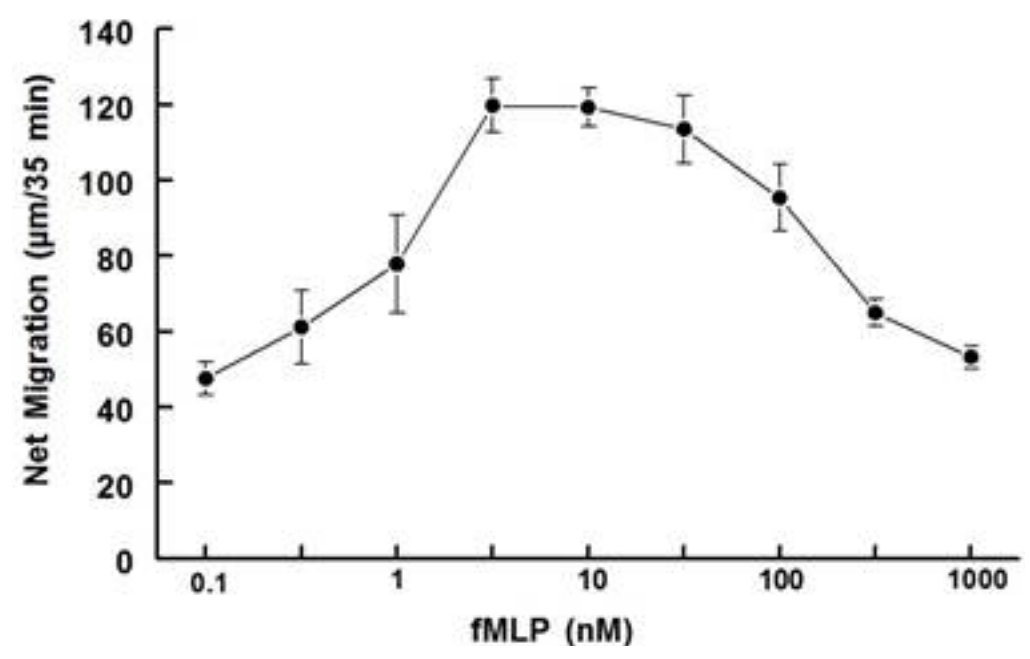

Figure 1. Concentration response curve of fMLP-induced chemotaxis by human neutrophils. The leading front method of chemotaxis was used. $n=5$.

Aldrich). Filters were viewed microscopically and neutrophil movement into the filter was quantified by identifying distance traveled by the leading two neutrophils, hence the reason the procedure is called the leading front assay. Net neutrophil migration into the filter was determined using the formula: (distance moved in response to treatment) minus (distance moved in response to buffer) $=$ net migration of neutrophil movement in $\mu \mathrm{m} / 35 \mathrm{~min}$. $A$ suboptimal concentration of fMLP was used for testing plantderived compounds in order to determine whether inhibition or augmentation of neutrophil movement resulted.

\section{Statistical analysis}

All data were reported as the mean \pm SEM. Comparisons of sample means were analyzed using repeated measures ANOVA followed by Dunnett multiple comparisons. Differences with $p<0.05$ were considered significant.

\section{RESULTS}

\section{fMLP concentration response curve}

Results of the fMLP concentration response curve indicated that peak neutrophil movement was at $5 \mathrm{nM}$ fMLP (Figure 1). Suboptimal concentrations were 0.5 and $1 \mathrm{nM}$ fMLP. Declining neutrophil chemotaxis was evident at 50 to $1,000 \mathrm{nM} \mathrm{fMLP}$.

\section{Neutrophil chemotaxis after pretreatment with plant- derived compounds}

The suboptimal concentration of $0.5 \mathrm{nM}$ fMLP was used for assessment of effects of phytochemical-pretreatment on neutrophils. Several concentrations of phytochemicals $(0,0.01,0.1,1,10,100 \mathrm{uM})$ were assessed to determine their effects on neutrophil chemotaxis. Curcumin significantly inhibited fMLP-induced neutrophil chemotaxis in a concentration-dependent manner with statistically significant inhibition at 50 and $100 \mu \mathrm{M}$ (Figure $2 \mathrm{~A})$ whereas vehicle $(0.1 \% \mathrm{DMSO})$ had no effect on the chemotaxis (data not shown). Resveratrol inhibited fMLPinduced chemotaxis in a concentration-dependent manner with statistically significant inhibition at 25, 50 and $100 \mu \mathrm{M}$ (Figure 2B). Rosmarinic acid inhibited fMLPinduced neutrophil chemotaxis in a concentrationdependent manner with statistically significant inhibition evident at $100 \mu \mathrm{M}$ (Figure 2C). Piperine had no effect on fMLP-induced chemotaxis of neutrophils (Figure 2D). Trypan blue viability assays were performed in parallel with chemotaxis assays using the highest concentrations of all agents tested. None of the agents tested had any effect on PMN viability.

\section{DISCUSSION}

Neutrophils are actively recruited to sites of tissue infection and/or injury by directed movement (chemotaxis). In vitro assessment of inhibition of neutrophil chemotaxis is a physiologic indicator of antiinflammatory potential (Antonicelli et al., 2004). The concentration response curve of fMLP showed suboptimal (0.5 and $1 \mathrm{nM} \mathrm{fMLP})$, peak ( $5 \mathrm{nM} \mathrm{fMLP}$ ) and declining (50 to $1,000 \mathrm{nM}$ fMLP) neutrophil chemotaxis. Use of suboptimal concentrations allowed for interpretation of augmentation as well as inhibition outcomes. Declining chemotaxis at higher fMLP concentrations was not used due to the desensitization of neutrophil surface receptors to fMLP at those concentrations.

Plant-derived compounds (curcumin, resveratrol, rosmarinic acid, piperine) were assessed for effects on in 
A

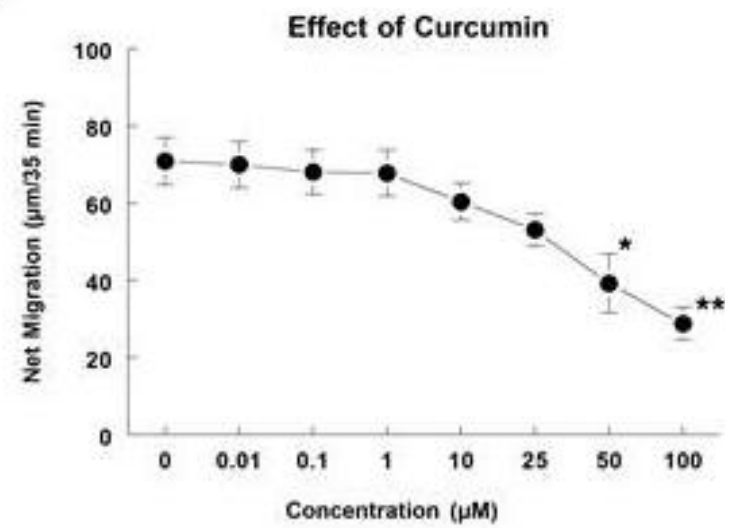

C

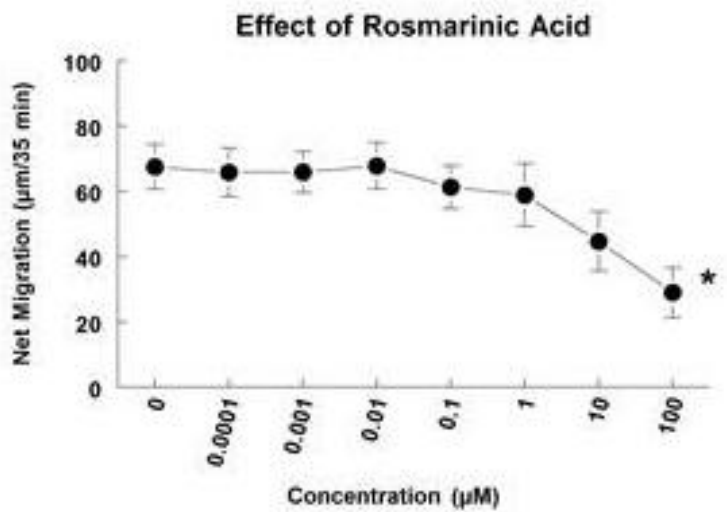

B

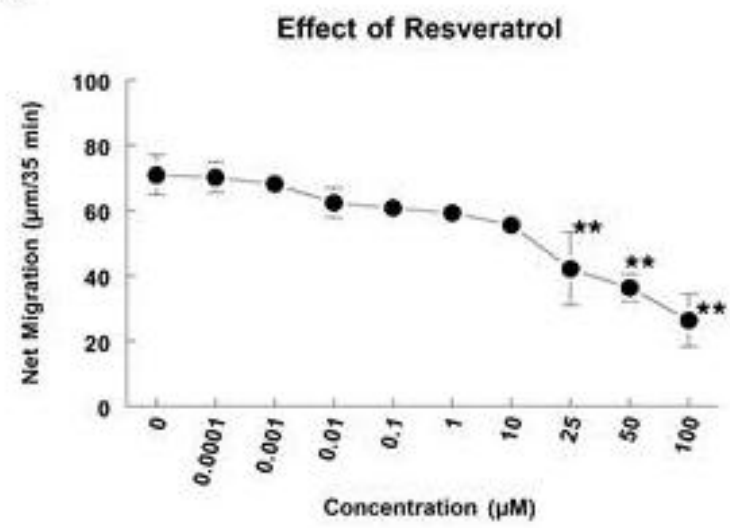

D

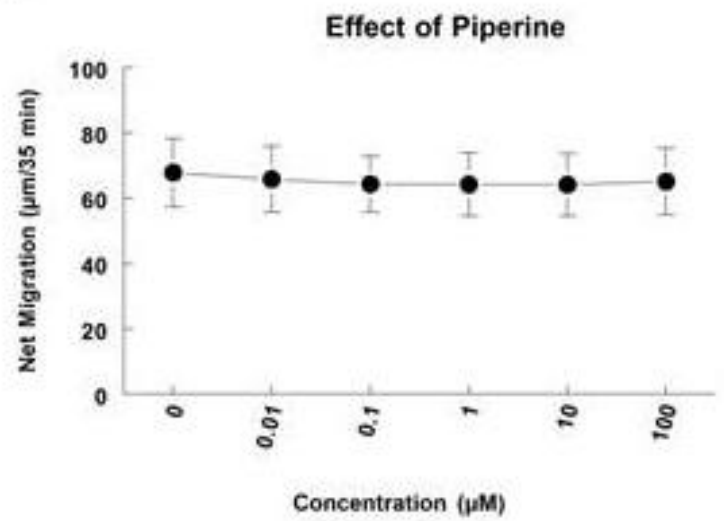

Figure 2. Effect of phytochemicals on fMLP-induced chemotaxis of human neutrophils. Cells were pretreated (10 minutes, $37^{\circ} \mathrm{C}$ ) with indicated compounds and concentrations and then added to the chemotaxis unit for assessment of fMLP $(0.5 \mathrm{nM})$-induced chemotactic movement by the leading front method. A. Curcumin concentration response curve. $n=6$ at each concentration. B. Resveratrol concentration response curve. $n=6$ at each concentration. C. Rosmarinic acid concentration response curve. $n=6$ at each concentration. D. Piperine concentration response curve. $n=3$ at each concentration. For all panels: ${ }^{*}=p<0.05$ versus fMLP alone $(0$ concentration of plant compound $) .{ }^{* *}=p<0.01$ versus fMLP alone (0 concentration of plant compound).

vitro neutrophil movement, that is, on chemotaxis towards the potent chemoattractant of bacterial cell wall origin, $f-$ met-leu-phe (fMLP). Recent studies have shown that curcumin exerts anti-cancer activities on multiple types of cancer (Deguchi, 2015). For this reason, curcumin is one of the most promising phytochemicals that targets cancers and inflammation-mediated diseases. In the present study, curcumin significantly inhibited neutrophil chemotaxis in a concentration-dependent manner with statistically significant inhibition at 50 and $100 \mu \mathrm{M}$ (Figure 2A). Neutrophil chemotaxis to an IL-8 homologue in mice (MIP-2) proceeds through a signalling pathway that initiates at a G-protein-coupled receptor (CXCR2). Activation of this receptor renders an effect on F-actin polymerization in the lamellar region of the neutrophil through phosphoinositide 3-kinase (PI3K) and phosphatidylinositol $(3,4,5)$-trisphosphate $\quad\left(\mathrm{PI}(3,4,5) \mathrm{P}_{3}\right)$ pathway which includes protein kinase $B(A k t / P K B)$ and guanosine triphosphatases Cdc42 and Rac 2. Larmonier et al. (2011), showed that curcumin inhibited actin formation at the leading edge of neutrophils during movement, an event that involved $\mathrm{PI} 3 \mathrm{~K}$ and $\mathrm{PI}\left(3,4,5 \mathrm{P}_{3}\right)$. The finding that ERK phosphorylation was not affected indicated that the curcumin effect was not targeted to initial stages of MIP-2/CXCR2 signal transduction in the neutrophil. The inhibitory effect herein reported may be due to regulation of $\mathrm{F}$-actin polymerization through phosphoinositide 3-kinase (PI3K) and phosphatidylinositol $(3,4,5)$-trisphosphate $\left(\mathrm{PI}(3,4,5) \mathrm{P}_{3}\right)$ in the lamellar region of a migrating neutrophil, all of which are vital components of leading edge formation (Larmonier et al, 2011). 
Resveratrol, the polyphenol present in skins of red grapes and in red wines, has been linked with antiinflammatory and anti-cancer activities (Inoue and Nakata, 2015; Wang et al., 2015). It is herein shown that resveratrol inhibited fMLP-induced chemotaxis in a concentration-dependent manner with statistically significant inhibition at 25, 50 and $100 \mu \mathrm{M}$ (Figure 2B). This result confirms prior reports (Inoue and Nakata, 2015; Wang et al., 2015) that resveratrol has antiinflammatory activities. Inoue and Nakata state that resveratrol is a phytoalexin indicating that it is an antimicrobic synthesized by plants in response to assault by pathogenic bacteria or environmental stresses with resultant resistance to infection and stresses. Other antiinflammatory processes ascribed to resveratrol are cyclooxygenase inhibition (Inoue and Nakata, 2015) and prevention of cytokine-induced vascular leakage (Wang, Dabrosin et al. 2015).

Rosmarinic acid from Rosmarinus officinalis has been shown to be anti-inflammatory in vivo by reducing number of leukocytes that roll, adhere and migrate to an inflamed site after injection of inflammatory agents in a rat model (Nogueira de Melo et al., 2011). Following up on this report, the question was posed as to whether purified rosmarinic acid rendered a similar effect in vitro as rosemary essential oil did in vivo. As shown herein, rosmarinic aid displayed significant anti-chemotactic effect, albeit at a single concentration (100 uM: Figure $2 \mathrm{C})$. To our knowledge, this is the first report of inhibition of chemotaxis of human neutrophils by rosmarinic acid.

While piperine from Piper nigrum has been reported to have anti-inflammatory (Mujumdar et al., 1990; Sunila and Kuttan, 2004) and pro-inflammatory properties (Mujumdar et al., 1990; Sunila and Kuttan, 2004), piperine exhibited no effect on fMLP-induced neutrophil chemotaxis at the doses tested (Figure 2D). Mujumdar and Dhuley assessed piperine action in in vivo acute and chronic models of inflammation and identified that an anti-inflammatory piperine action was significantly manifested during acute inflammation at early stages. However, Sunila and Kuttan assessed piperine effect on solid tumor development and found that piperine increased total leukocyte number at the tumor site thereby implicating phagocyte recruitment and proinflammatory processes at the site. In another study, chemotaxis of macrophages (cell line Raw 264.7 of murine origin) was inhibited by piperine in a dosedependent manner at concentrations similar to those used in the current study (Woo et al., 2007). It was therefore of interest to define the effect of piperine on chemotaxis of human neutrophils.

The present study identified the use of a well-established and long-used method to assess anti-inflammatory effects of phytochemicals, specifically the antiinflammatory effect of inhibition of neutrophil chemotaxis. Studies suggest that neutrophil and cancer cell movement share common features such as mechanisms of signal transduction, movement as receptor-mediated events and induction by chemokine chemoattractants (Soon, 2007; Wang, 2009). Therefore, prevention of chemotaxis by phytochemicals has the potential to alleviate disease conditions involving inflammation. As the inflammatory process becomes better elucidated, the list of diseases caused or affected by inflammation grows longer. Interestingly, links between cancer and inflammation have been identified, especially as related to cell movement (Lin and Karin, 2007). For this reason, effects of phytochemicals on cancer cell movement deserve assessment for antimetastasis potential. Future studies focus on mechanistic actions of these phytochemicals relevant to neutrophil chemotaxis.

\section{CONCLUSION}

Plant-derived compounds, such as resveratrol, curcumin and rosmarinic acid, inhibit chemotaxis of human neutrophils. These results indicate that phytochemicals have the ability to inhibit neutrophil recruitment to sites of infection and injury, and therefore have potential as antiinflammatory agents with mechanistic action targeted at initial step of the innate immune response.

\section{Conflicts of interest}

The authors declare no conflict of interest.

\section{ACKNOWLEDGEMENTS}

This work was funded in part by the Saint Louis University President Research Fund to URE.

\section{REFERENCES}

Antonicelli F, Brown D, Parmentier M, Drost EM, Hirani N, Rahman I, Donaldson K, MacNee W (2004). Regulation of LPS-mediated inflammation in vivo and in vitro by the thiol antioxidant Nacystelyn. Am. J. Physiol. Lung Cell Mol. Physiol. 286:L1319-1327.

Bardoel BW, Kenny EF, Sollberger G, Zychlinsky A (2014). The balancing act of neutrophils. Cell Host Microb. 15:526-536.

Boyum A (1968). Isolation of mononuclear cells and granulocytes from human blood. Isolation of mononuclear cells by one centrifugation, and of granulocytes by combining centrifugation and sedimentation at $1 \mathrm{~g}$. Scand. J. Clin. Lab. Invest. Suppl. 97:77-89.

Budhiraja A, Dhingra G (2014). Development and characterization of a novel antiacne niosomal gel of rosmarinic acid. Drug Deliv. [Epub ahead of print].

Costa RS, Carneiro TC, Cerqueira-Lima AT, Queiroz NV, AlcântaraNeves NM, Pontes-de-Carvalho LC, Velozo Eda S, Oliveira EJ, Figueiredo CA (2012). Ocimum gratissimum Linn. and rosmarinic acid, attenuate eosinophilic airway inflammation in an experimental model of respiratory allergy to Blomia tropicalis. Int. Immunopharmacol.13:126-134.

Deguchi A (2015). Curcumin targets in inflammation and cancer. Endocr. Metab. Immune Disord. Drug Targets. 15:88-96. den Broeder AA, Wanten GJ, Oyen WJ, Naber T, van Riel PL, 
Barrera P (2003). Neutrophil migration and production of reactive oxygen species during treatment with a fully human anti-tumor necrosis factor-alpha monoclonal antibody in patients with rheumatoid arthritis. J. Rheumatol. 30:232-237.

Dong Y, Huihui Z, Li C (2015). Piperine inhibit inflammation, alveolar bone loss and collagen fibers breakdown in a rat periodontitis model. J Periodontal Res. [Epub ahead of print].

Fang L, Gao H, Zhang W, Zhang W, Wang Y (2015). Resveratrol alleviates nerve injury after cerebral ischemia and reperfusion in mice by inhibiting inflammation and apoptosis. Int. J. Clin. Exp. Med. 8:3219-3226.

Hassan-Khabbar S, Vamy M, Cottart $\mathrm{CH}$, Wendum D, Vibert F, Savouret JF, Therond P, Clot JP, Waligora AJ, Nivet-Antoine V (2010). Protective effect of post-ischemic treatment with transresveratrol on cytokine production and neutrophil recruitment by rat liver. Biochimie 92:405-410.

Headland SE, Norling LV (2015). The resolution of inflammation: Principles and challenges. Semin. Immunol. 27(3):149-160

Heuertz RM, Tricomi SM, Ezekiel UR, Webster RO (1999). C-reactive protein inhibits chemotactic peptide-induced p38 mitogen-activated protein kinase activity and human neutrophil movement. J. Biol. Chem. 274:17968-17974.

Inoue H, Nakata R (2015). Resveratrol targets in inflammation. Endocr. Metab. Immune Disord. Drug Targets. J. Periodont. Res. [Epub ahead of print].

Kaur M, Singh D (2013). Neutrophil chemotaxis caused by chronic obstructive pulmonary disease alveolar macrophages: the role of CXCL8 and the receptors CXCR1/CXCR2. J. Pharmacol. Exp. Ther. 347:173-180.

Kinane DF, Cullen CF, Johnston FA, Evans CW (1989). Neutrophil chemotactic behaviour in patients with early-onset forms of periodontitis (I). Leading front analysis in Boyden chambers. J. Clin. Periodontol. 16:242-246.

Kolaczkowska E, Kubes $P$ (2013). Neutrophil recruitment and function in health and inflammation. Nat. Rev. Immunol. 13:159-175.

Kruger P, Saffarzadeh M, Weber AN, Rieber N, Radsak M, von Bernuth H, Benarafa C, Roos D, Skokowa J, Hartl D (2015). Neutrophils: Between host defence, immune modulation, and tissue injury. PLoS Pathog. 11:e1004651.

Larmonier CB, Midura-Kiela MT, Ramalingam R, Laubitz D, Janikashvili N, Larmonier N, Ghishan FK, Kiela PR (2011). Modulation of neutrophil motility by curcumin: implications for inflammatory bowel disease. Inflamm. Bowel Dis. 17:503-515.

Lin WW, Karin M (2007). A cytokine-mediated link between innate immunity, inflammation, and cancer. J. Clin. Invest. 117:1175-1183.

McCrea CE, West SG, Kris-Etherton PM, Lambert JD, Gaugler TL, Teeter DL, Sauder KA, Gu Y, Glisan SL, Skulas-Ray AC (2015). Effects of culinary spices and psychological stress on postprandial lipemia and lipase activity: results of a randomized crossover study and in vitro experiments. J. Transl. Med. 13:7.

McNeely MC, Lawley TJ, Harvath L (1993). Monoclonal antibody modulates human neutrophil chemotaxis to $\mathrm{N}$-formyl-methionylleucyl-phenylalanine (fMLP). J. Invest. Dermatol. 101:377-382.

Moghaddam SJ, Barta P, Mirabolfathinejad SG, Ammar-Aouchiche Z, Garza NT, Vo TT, Newman RA, Aggarwal BB, Evans CM, Tuvim MJ, Lotan R, Dickey BF (2009). Curcumin inhibits COPD-like airway inflammation and lung cancer progression in mice. Carcinogenesis 30:1949-1956.

Mujumdar AM, Dhuley JN, Deshmukh VK, Raman PH, Naik SR (1990). Anti-inflammatory activity of piperine. Jpn. J. Med. Sci. Biol. 43:95100.

Narumoto O, Matsuo Y, Sakaguchi M, Shoji S, Yamashita N, Schubert D, Abe K, Horiguchi K, Nagase T, Yamashita N (2012). Suppressive effects of a pyrazole derivative of curcumin on airway inflammation and remodeling. Exp. Mol. Pathol. 93:18-25.

Nogueira de Melo GA, Grespan R, Fonseca JP, Farinha TO, Silva EL, Romero AL, Bersani-Amado CA, Cuman RK (2011). Rosmarinus officinalis L. essential oil inhibits in vivo and in vitro leukocyte migration. J. Med. Food 14:944-946.

Nonose N, Pereira JA, Machado PR, Rodrigues MR, Sato DT, Martinez CA (2014). Oral administration of curcumin (Curcuma longa) can attenuate the neutrophil inflammatory response in zymosan-induced arthritis in rats. Acta Cir Bras 29:727-734.

Pearson W, Fletcher RS, Kott LS (2012). Oral rosmarinic acidenhanced Mentha spicata modulates synovial fluid biomarkers of inflammation in horses challenged with intra-articular LPS. J. Vet. Pharmacol. Ther. 35:495-502.

Rocha J, Eduardo-Figueira M, Barateiro A, Fernandes A, Brites D, Bronze R, Duarte CM, Serra AT, Pinto R, Freitas M, Fernandes E, Silva-Lima B, Mota-Filipe H, Sepodes B (2015). Anti-inflammatory effect of rosmarinic acid and an extract of Rosmarinus officinalis in rat models of local and systemic inflammation. Basic Clin. Pharmacol. Toxicol. 116:398-413.

Sabina EP, Nagar S, Rasool M (2011). A role of piperine on monosodium urate crystal-induced inflammation--an experimental model of gouty arthritis. Inflammation 34:184-192.

Soon LL (2007). A discourse on cancer cell chemotaxis: where to from here? IUBMB Life 59:60-67.

Sunila ES, Kuttan G (2004). Immunomodulatory and antitumor activity of Piper longum Linn. and piperine. J. Ethnopharmacol. 90:339-346.

Vaibhav K, Shrivastava P, Javed H, Khan A, Ahmed ME, Tabassum R, Khan MM, Khuwaja G, Islam F, Siddiqui MS, Safhi MM, Islam F (2012). Piperine suppresses cerebral ischemia- reperfusion-induced inflammation through the repression of COX- 2, NOS-2, and NF$\mathrm{KB}$ in middle cerebral artery occlusion rat model. Mol. Cell Biochem. 367:73-84.

Wang $F$ (2009). The signaling mechanisms underlying cell polarity and chemotaxis. Cold Spring Harb. Perspect. Biol. 1:4.

Wang Z, Dabrosin C, Yin X, Fuster MM, Arreola A, Rathmell WK, Generali D, Nagaraju GP, El-Rayes B, Ribatti D, Chen YC, Honoki K, Fujii H, Georgakilas AG, Nowsheen S, Amedei A, Niccolai E, Amin A, Ashraf SS, Helferich B, Yang X, Guha G, Bhakta D, Ciriolo MR, Aquilano K, Chen S, Halicka D, Mohammed SI, Azmi AS, Bilsland A, Keith WN, Jensen LD (2015). Broad targeting of angiogenesis for cancer prevention and therapy. Semin. Cancer Biol. pii:S1044579X(15)00002-4

Woo HM, Kang JH, Kawada T, Yoo H, Sung MK, Yu R (2007). Active spice-derived components can inhibit inflammatory responses of adipose tissue in obesity by suppressing inflammatory actions of macrophages and release of monocyte chemoattractant protein-1 from adipocytes. Life Sci. 80:926-931.

Zang N, Li S, Li W, Xie X, Ren L, Long X, Xie J, Deng Y, Fu Z, Xu F, Liu E (2015.) Resveratrol suppresses persistent airway inflammation and hyperresponsivess might partially via nerve growth factor in respiratory syncytial virus-infected mice. Int. Immunopharmacol. 28: 121-128.

Zigmond SH, Hirsch JG (1973.) Leukocyte locomotion and chemotaxis. New methods for evaluation, and demonstration of a cell-derived chemotactic factor. J. Exp. Med. 137:387-410. 